\title{
Intersetorialidade nas políticas públicas ${ }^{1}$
}

\author{
Intersectoriality in public policies
}

Silvana Marta Tumelero ${ }^{2}$

\begin{abstract}
Resumo
Este ensaio, produzido a partir de pesquisa bibliográfica, objetiva apresentar o debate de intersetorialidade sob abordagens teórico-conceituais que a aproximam das perspectivas de "interdisciplinaridade" e da "transdisciplinaridade. Sob o recurso metodológico da análise documental, tomando por base o texto da Constituição brasileira de 1988, problematiza o sentido que é atribuído à intersetorialidade no cotidiano das políticas públicas. $\mathrm{O}$ ensaio se propõe também a refletir sobre as possibilidades de superação de práticas fragmentárias ou sobrepostas na relação com os usuários de serviços estatais. No Brasil, as ações governamentais integradas, intersetorial e interinstitucionalmente são indicativos para a execução de várias políticas públicas federais. Entretanto, as políticas públicas de caráter social, sob a lógica jurídico-administrativa da descentralização, nos revelam que em governos municipais, as práticas intersetoriais, quando ocorrem, ainda figuram como processos inovadores e experimentais, viabilizados mais pelo interesse de seus agentes, do que por uma decisão política de governo. Neste sentido o ensaio sinaliza dimensões sob as quais é possível o aprofundamento do debate da intersetorialidade, sua consecução interdependente da lógica territorial de operacionalização de políticas públicas e de reflexões no campo ético-político da gestão, contrapondo-se à perspectiva gerencial, eixo do neoliberalismo político.
\end{abstract}

Palavras-chave: Intersetorialidade. Políticas Públicas. Políticas sociais.

\begin{abstract}
This essay, produced from a bibliographical research, aims to present the intersectoral debate under theoretical and conceptual approaches that bring it closer to the perspectives of "interdisciplinarity" and "transdisciplinarity. Under the method of documental analysis, after the reading of the Brazilian Constitution of 1988, it reflects the meaning attributed to the intersectoriality in the daily of public policies. The essay also proposes to reflect on the possibility of overcoming fragmentary or overlapping practices in the relationship with users of state services. In Brazil, governmental actions, integrated from the intersectoral and interinstitutionally, are indicative for the execution of several federal public policies. However, public policies of a social nature, under the legaladministrative logic of decentralization, are expressed as innovative and experimental processes in municipal governments and intersectoral practices, when they are performed, still figure as innovative and experimental processes, enable the motivation of their agents than by a political decision of the government. In this sense the essay indicates dimensions under which it is possible

\footnotetext{
${ }^{1}$ Versão preliminar deste artigo foi apresentada no III Congresso Internacional do Conhecimento "Ciências, tecnologias e culturas - Diálogos entre as disciplinas do conhecimento. Um olhar sobre o futuro da América Latina e Caribe", Simpósio 46 - Democracia, governo e políticas públicas: estratégicas para o desenvolvimento regional, em Santiago, Chile, jan. 2013.

2 Doutora em Serviço Social (UFSC). Professora da Universidade Federal do Paraná, Setor Litoral. E-mail: siltumelero.ufpr@gmail.com
} 
to deepen the debate of intersectoriality, its interdependent achievement of the territorial logic of operationalization of public policies and of reflections in the ethical-political field of management, in opposition to the managerial perspective, axis of political neoliberalism.

Keywords: Intersectoriality. Public policies. Social policies.

\section{Introdução}

Contemporaneamente o tema intersetorialidade figura sob distintas abordagens, tanto nas políticas governamentais quanto nos debates acadêmicos. Nas políticas públicas, a intersetorialidade aparece como possibilidade de superação de práticas fragmentárias ou sobrepostas, na relação com os usuários de serviços estatais, ou mesmo de serviços ofertados por organizações privadas sob iniciativas da sociedade civil ou de fundações empresariais. No campo das produções intelectuais, a intersetorialidade é identificada em sua problematização conceitual, sob análises de paradigmas gerenciais, em teorias da administração pública e em debates acerca das finalidades de seu uso, sob o ponto de vista ético, político e de projetos societários.

No Estado brasileiro, afirmado pela Constituição Federal de 1988, o indicativo de ações governamentais integradas, intersetorial e interinstitucionalmente, constitui diretriz para várias políticas públicas destinadas a assegurar direitos. Apesar disto e transcorridas aproximadamente três décadas da promulgação da Constituição, as práticas intersetoriais ainda figuram como processos inovadores e experimentais, viabilizados na maioria das situações pelo interesse dos atores que executam tais políticas e, menos, por uma decisão de governo - são poucas as experiências em que administrações municipais optam por um desenho de governo pautado na intersetorialidade ${ }^{3}$.

O preâmbulo do texto constitucional (BRASIL, 2009) reconhece o Brasil como Estado democrático de direito, cujos valores se pautam na garantia de "direitos sociais e individuais, liberdade, segurança, bem-estar, desenvolvimento, igualdade e justiça", os quais não têm um significado universal, mas são mediados pelos referenciais ético-políticos que orientam as práticas humanas/sociais e, por conseguinte, as práticas governamentais. No próprio texto constitucional é possível identificar o caráter contraditório do Estado, a exemplo de quando submete à ordem econômica e não à ordem social, o trabalho, a função social da propriedade, a política urbana, a política agrícola, fundiária e a reforma agrária, explicitando a primazia da lógica capitalista na

\footnotetext{
${ }^{3}$ Experiências referidas de intersetorialidade que buscam o reconhecimento internacional de "Cidades Saudáveis", com ações intersetoriais para melhoria da qualidade de vida da população, ou experiências de gestão com Orçamento Participativo, sob mobilizações intersetoriais para definição de prioridades no uso de recursos públicos, estão em: Neves (2008); Avritzer e Navarro (2003); Inojosa e Junqueira (1997).
} 
abordagem dessas necessidades/direitos sociais ${ }^{4}$, os quais, em tese, deveriam compor direitos sociais elementares.

Frente ao exposto, este ensaio objetiva trazer reflexões éticas e políticas que permitam fundamentar a gestão intersetorial de políticas públicas para além do seu alcance gerencial. O texto está estruturado em 3 itens, além desta introdução e das considerações finais. O item 2, parte de uma análise documental de políticas sociais presentes na Constituição Federal de 1988, buscando identificar diretrizes que evidenciem a necessidade de ações intersetoriais. Na parte inicial deste item, demarcamos nosso entendimento conceitual de políticas públicas, para, na sequência, passar a análise do texto constitucional. O item 3 centra-se nas abordagens conceituais de intersetorialidade, as quais, a partir de análise bibliográfica, classificamos, tanto em noções de intersetorialidade na execução de políticas públicas e sua gestão jurídico-administrativa, quanto a aproximações epistemológicas/conceituais e a dimensão ético-política da intersetorialidade. O item 4 faz uma síntese reflexiva sobre os dilemas da gestão intersetorial e saídas possíveis.

Esperamos que este ensaio contribua com os agentes implementadores de políticas públicas no aprimoramento dos processos intersetoriais vivenciados no cotidiano de seu trabalho.

\section{Políticas públicas no Estado brasileiro e intersetorialidade}

Para as problematizações sobre a gestão intersetorial cabe explicitarmos a concepção de políticas públicas que adotamos, visto que nesse âmbito, se intencionam e concretizam tais ações.

De modo breve recorremos à Pereira $(2009$, p. 87$)$ para esclarecer que além dos "temas clássicos da política, como eleições, voto, partido, parlamento, governo [...] há também um sentido mais recente e restrito, que se refere às ações do Estado face às demandas e necessidades sociais" de sua população, se traduzindo como política pública. Esta é integrante da área de conhecimento denominada ciência política que tem sua emergência no contexto pós II Guerra, nos Estados Unidos e na Europa, sob a busca da compreensão da "dinâmica das relações entre governos e cidadãos", para além dos aspectos normativos e morais do "funcionamento de instituições específicas" (PEREIRA, 2009, p.92).

Relativo à compreensão da política pública como ramo de conhecimento, Lasswell (apud PEREIRA, 2009), identifica três características centrais: “é multidisciplinar [...] é intervencionista [...] e é normativa" (p.93). A multidisciplinaridade se expressa na abordagem de temas e questões

\footnotetext{
${ }^{4}$ Por tais razões optamos por discutir a intersetorialidade nas políticas públicas e não particularizada ao campo da política social.
} 
por diversas disciplinas científicas. Sua característica intervencionista se dá porque a política pública não se limita em conhecer um objeto de estudo, mas busca interferir nele e alterá-lo. E por fim, o caráter normativo da política pública ocorre na sua execução, quando "[...] se defronta com a impossibilidade de separar fins e meios, bem como valores e técnicas, no estudo das ações dos governos" (LASSWELL apud PEREIRA, 2009, p.93).

No Estado de direito, a compreensão de política pública porta a noção de que as dificuldades encontradas pela sociedade na resolução de suas necessidades, serão assumidas coletivamente "com supremacia da responsabilidade de cobertura do Estado, que deverá criar um sistema institucional capaz de dar conta dessas demandas" (COUTO, 2008, p.183). E, considerando que necessidades e problemáticas sociais tem como características serem complexas e multidimensionais, seus enfrentamentos não podem ocorrer exclusivamente sob perspectiva setorializada, mas, segundo Raichelis (2008, p.212), "por meio da intersetorialidade é possível abordar de forma mais ampla" tais situações, lhes dirigindo soluções de maior efetividade.

Para que possamos empreender problematizações da intersetorialidade nas políticas públicas, percorremos de modo analítico o texto constitucional, buscando apreender diretrizes e/ou indicativos de gestão intersetorial nas políticas públicas, que são apresentadas a seguir.

No que concerne à definição de seguridade social, o art. 194 a explicita como "um conjunto integrado de ações de iniciativa dos poderes públicos e da sociedade”. Ao tratar do direito à saúde, o art. 196 deixa claro que esse será "garantido mediante políticas sociais e econômicas" tendo sua execução "feita diretamente ou através de terceiros e, também, por pessoa física ou jurídica de direito privado", conforme art. 197. E, somente no art. 198 é que se apresenta o direito à saúde como decorrente da atuação do Estado, na forma de serviços que "integram uma rede regionalizada e hierarquizada" constituindo um "sistema único" (BRASIL, 2009).

Esse exemplo que tem a saúde como referência, nos permite perceber que a gestão intersetorial demanda integrações de políticas de diferentes naturezas (neste caso de caráter econômico e social); articulação de diferentes atores, os quais, sem sombra de dúvidas possuem interesses divergentes, dado ao lugar que ocupam na relação com a política de saúde e principalmente à dimensão ética de sua práxis (se usuário, prestador de serviço privado, servidor público, ou outra); relação verticalizada em diferentes níveis da gestão pública (federal, estadual e municipal). Mostra ainda o caráter contraditório e conflitante na consecução desse direito "universal", de um lado, sob a responsabilidade do Estado, mas por outro, com permissão à lógica mercantil. 
Conforme afirma Sader (2004, p.7), na década de 1990 e início dos anos 2000, o Estado brasileiro diminuiu os recursos para políticas sociais e viabilizou a "expansão dos serviços privados [os quais] restringiram a proporção da população com acesso a direitos [e ampliaram o papel] desempenhado pelos mercados como reguladores das relações sociais. E os mercados como se sabe, não reconhecem direitos".

Retornando ao texto constitucional, é possível identificarmos a orientação da ação integrada sob perspectiva similar à lógica problematizada na saúde, na política de educação - "O ensino é livre à iniciativa privada" (BRASIL, 2009, art. 209) que permite a consecução dos serviços públicos como mercadorias obtidas no âmbito privado. O indicativo de ação intersetorial mencionado no art. 205 se refere à educação "promovida e incentivada com a colaboração da sociedade, visando ao pleno desenvolvimento da pessoa, seu preparo para o exercício da cidadania e sua qualificação para o trabalho", o que demanda no mínimo, diálogos com políticas de direitos humanos, de assistência social e trabalho. Também aparece o indicativo de articulação do sistema de ensino nos três níveis da gestão pública, explicitando a necessária integração de níveis de execução da política de educação.

A previdência social, apesar de fazer parte da seguridade social, que por si deveria traduzirse como política integrada, permanece, constitucionalmente, com operacionalização setorializada, não constando qualquer menção à intersetorialidade. Esta política tem como orientação à sua organização, a observância de "critérios que preservem o equilíbrio financeiro" - art. 201. Inúmeras críticas se colocam a endogenia administrativa da previdência social, tendo sido forçada a diálogos intersetoriais por demandas das demais políticas integrantes da seguridade - a exemplo da administração dos recursos dos Benefícios de Prestação Continuada (BPC), da área de assistência social e das ações no âmbito da saúde do trabalhador (perícia médica e reabilitação). Recentemente, em 2016, através de uma reforma administrativa implantada pelo governo federal, o Ministério da Previdência Social foi extinto e transformado em uma secretaria do Ministério da Fazenda, o que corrobora nossa análise da predominância do interesse econômico financeiro sobre tal política.

De modo similar às demais políticas mencionadas, o meio ambiente é área que implica planejamento e ação articulada às demais políticas, dada a sua complexidade. Entretanto no texto constitucional a ação intersetorial possível de ser evidenciada, concerne ao que atribui ao "Estado e à coletividade o dever de defendê-lo" - art. 225 (BRASIL, 2009).

No que se refere à previsão constitucional da política de assistência social se percebe que ela não é objeto de interesses do mercado, como alvo de mercantilização de serviços. Entretanto é de interesses de setores da sociedade civil que disputam espaços políticos para práticas que se 
configuram ora como conservadoras, clientelistas, ora como integrantes de experiências inovadoras no campo das garantias de direitos. O que é possível concluir quanto à intersetorialidade é que, no âmbito da política de assistência social, ela pode ser apreendida de modo complexo, por vários significados, seja a integração de ações nos três níveis de governo e com a sociedade civil organizada, para a sua operacionalização, ou na ampliação dos atores políticos a quem compete sua formulação, acompanhamento da execução e controle social. Por ser executada com orçamento da seguridade social, demandará diálogos com as políticas de saúde e previdência social (BRASIL, 2009, art. 204).

A política de cultura tem previsão de ser executada sob coordenação, autorização e regulação de instâncias estatais, entretanto seu financiamento é condicionado a apoiadores privados, mediante leis de incentivo à cultura. Consoante ao que dispõe o $§ 1^{\circ}$ do art. 216, "o Poder Público, com a colaboração da comunidade, promoverá e protegerá o patrimônio cultural brasileiro" (BRASIL, 2009).

Ainda que a intersetorialidade conste como diretriz explícita ou implícita em várias políticas públicas, inúmeros são os entraves constatados na sua operacionalização, a iniciar por suas configurações e operacionalizações condicionadas a desenhos jurídico-administrativos setoriais nos três níveis de governo (ex. Ministérios e Secretarias). Além deste aspecto, é relevante que reconheçamos uma preocupação central do Estado brasileiro com a ordem capitalista e a propriedade privada, bem como a frequente recorrência, na gestão pública, a paradigmas da gestão privada.

No Brasil é possível identificar a esfera pública composta de inúmeros atores que não apenas aqueles circunscritos ao quadro funcional estatal, o que indica a necessária problematização dos parâmetros e referenciais utilizados na gestão e execução das políticas públicas.

Outros aspectos marcantes como entraves às práticas intersetoriais são, "estruturas marcadas pela fragmentação, excessiva burocratização, paralelismo de ações, endogenia de departamentos, entre outros" (SCHUTZ, 2009, p.14).

Inojosa demarca três situações identificadas no aparato governamental que se tornam empecilhos à intersetorialidade. Tal aparato "é todo fatiado por conhecimentos, por saberes, por corporações [...] outra herança, que é a hierarquia verticalizada, piramidal, em que os processos percorrem vários escalões, mas as decisões são tomadas apenas no topo [...] é objeto de loteamento político-partidário e de grupos de interesse" (INOJOSA, 2001, p.103-104).

Além da leitura que fazemos da intersetorialidade, como diretriz das políticas públicas de caráter social, quando nos referimos ao tema do orçamento e financiamento das políticas públicas, 
salta aos olhos as disputas entre grupos de interesses distintos, sejam eles representantes de segmentos da sociedade civil, que possam de algum modo acessar determinados recursos públicos, grupos econômicos com forte representação política no Congresso, ou até mesmo, disputas intersetoriais dos próprios órgãos governamentais.

De acordo com Inojosa (2001, p.104) essas disputas e fatiamentos do orçamento integram "uma lógica que não tem nada a ver com a necessidade das pessoas ou dos grupos populacionais, [nas suas necessidades/particularidades sociais territoriais] que precisam integradamente de condições de desenvolvimento social, de condições ambientais e de infra-estrutura".

Além das disputas que dificultam a execução de prioridades intersetoriais, visto o limite orçamentário de muitos programas - ditos prioritários pelo governo, o "orçamento torna-se aquela peça de ficção que revela muito bem as clausuras setoriais, a separação dos setores, a competição entre os grupos de interesse que ocupam os vários setores" (INOJOSA, 2001, p. 105).

Ao nos referirmos à intersetorialidade é importante pontuar que a estrutura segmentada dos governos, em saberes e conhecimentos setorizados e especializados, tem efeitos sobre os usuários dos serviços públicos, os quais não são percebidos como integrantes de uma realidade de múltiplas determinações que também inclui aspectos subjetivos.

Muito frequentemente os usuários dos serviços públicos são qualificados pelas suas necessidades e vulnerabilidades objetivas, apreendidas de modo fragmentado por saberes disciplinares, não tendo respeitada sua dimensão de sujeito humano/social e, por conseguinte, as ações dos operadores das políticas públicas, distanciam-se de práticas que possam contribuir para a construção da autonomia e atuação política desses sujeitos.

Tais elementos são reforçados pela cultura política nacional, impregnada de direcionamentos clientelistas, paternalistas, cunhada pelo personalismo político e internalizada na dinâmica organizacional do aparato estatal brasileiro.

A lógica setorial facilita a explicitação de demandas particulares da população, na busca de soluções imediatas, o que compromete a existência de espaços públicos de debates ampliados (intersetoriais) que possam explicitar distintos projetos de sociedade, de Estado e de governos.

O desenho do atual Estado brasileiro democrático e de direito, tem forte apelo à relação com a sociedade civil, seja nos processos de participação política direta ou em espaços e mecanismos institucionalizados que atribuem a atores políticos (coletividades da sociedade civil organizada) poder deliberativo e fiscalizador na execução das políticas públicas, sob os princípios da descentralização político-administrativa e da participação social. 
Essa lógica se coloca como desafiadora à implementação de processos intersetoriais, visto que explicita jogos de poder e conflitos, polarizando grupos de defesa de interesses públicos de largo alcance social e portadores do discurso mercantil. Neste sentido, se pontuam como entraves para a consecução de políticas intersetoriais, a presença das redes sociais que se integram e articulam constituindo-se como alternativa de descentralização para a gestão das políticas sociais. Esta é uma variável que tensiona as relações entre Estado e sociedade e demanda esforço de gestão e negociação política para práticas intersetoriais, visto ser um espaço mediado pela diversidade de valores - associados a motivações e/ou pautas específicas, tais como as religiosas, doutrinárias, corporativas, mercantis, clientelistas, dentre outras.

A seguir abordamos as conceituações de intersetorialidade que frequentemente aparecem associadas aos relatos e análises da implementação de políticas e programas sociais.

\section{Abordagens conceituais sobre intersetorialidade}

Em leituras preliminares sobre a temática da intersetorialidade identificamos várias conceituações que merecem destaque para as reflexões que apresentamos na sequência, em subitens.

\section{Noções de intersetorialidade na execução de políticas públicas}

A primeira noção a que nos referimos, tem o sentido de complementaridade de setores e é definida como "ações integradas de distintos setores, no atendimento da população, cujas necessidades são pensadas a partir de sua realidade concreta, de modo a colocar em pauta as peculiaridades de suas condições de vida" (SCHUTZ, 2009, p.16).

Neste mesmo sentido de complementaridade de setores, a intersetorialidade se refere a “conjuntos de projetos que eventualmente estabelecem algum diálogo na hora da formulação ou da avaliação" (INOJOSA, 2001, p. 105).

A intersetorialidade como prática é outra visão identificada por Schutz (2009) que visualiza nas ações integradas sob diferentes saberes, a possibilidade de constantes aprendizados, pelo relato do "fazer", ainda que sob perspectiva de cada setor, na abordagem de uma determinada realidade territorialmente localizada. No nosso entendimento, ambas são restritas, pois se referem à complementaridade/integração de ações, ou dão ênfase aos saberes circunscritos a cada setor, como se fosse possível a constituição de políticas públicas, cujo conhecimento permanecesse sob uma 
perspectiva disciplinar, ou, de um saber que lhe é exclusivo, reconhecida a complexidade da realidade demandatária da intervenção do Estado. Neste aspecto concordamos com Pereira (2011, p. 4) ao afirmar que o termo setor "é um arranjo técnico ou burocrático criado para facilitar a gestão das demandas que pululam no universo complexo da política social e nas arenas de conflito que nesse universo se estabelecem".

A terceira das dimensões apontadas, pode ser apreendida pelo sentido de articulação política na gestão pública identificada em orientações de governos na implementação da intersetorialidade. Apresentada na concepção da Secretaria de Saúde Municipal do Rio de Janeiro (2011) e da Rede Unida (apud Schutz, 2009), a intersetorialidade compreende a articulação entre sujeitos de setores sociais diversos, portadores de saberes, poderes políticos e interesses distintos, objetivando o enfrentamento de problemas complexos.

Junqueira (2004), além de afirmar a finalidade da intersetorialidade como busca de soluções para a "complexidade da realidade social", também considera interesses distintos dos atores envolvidos na superação de problemas sociais. Nesta lógica, a intersetorialidade se configura por ações e decisões compartilhadas, tanto em pesquisas para identificação das necessidades sociais, quanto no planejamento e na avaliação das políticas públicas.

Uma quarta conceituação atribui à intersetorialidade a tarefa de otimização de recursos públicos na operacionalização de soluções integradas aos problemas da realidade social. (JUNQUEIRA, 2004). Neste enfoque há aceitação de práticas intersetoriais sob a perspectiva da racionalidade gerencial do Estado. Apresenta-se como ferramenta tecnocrática, uma perspectiva de atuação que não implica partilha de poderes, crescimento político, compreensão mais aprofundada das múltiplas dimensões que compõem a realidade social.

Uma quinta noção da intersetorialidade pode ser apreendida como trabalho com redes, ou seja, ações conjuntas - principalmente no âmbito municipal - que visam atender aos segmentos vulnerabilizados, sob práticas que primam por conexões entre atores sob relações horizontais, construindo ações complementares e integradas.

Além das perspectivas evidenciadas anteriormente, apreendemos três dimensões presentes nos debates atuais de intersetorialidade, indissociáveis entre si, que categorizamos a seguir, com o objetivo de elucidar aspectos que desejamos aprofundar neste artigo.

Uma dessas dimensões se configura pela problematização e/ou abordagem epistemológica conceitual da intersetorialidade. A segunda delas a que denominamos dimensão ético-política da intersetorialidade, compreende a necessária explicitação dos projetos ideo-políticos envolvidos e em disputa no espaço público, as correlações de forças e jogos de interesses implicados nesse campo, 
que não se circunscrevem aos atores diretamente vinculados ao Estado, mas aos demais sujeitos, que atuam no âmbito do chamado terceiro setor ou do mercado. E, por fim, a terceira dessas dimensões é a gestão jurídico-administrativa que não se dissocia das anteriores, mas explicita instrumentos técnicos e marcos legais de suporte à gestão intersetorial, as quais detalharemos nos próximos subitens.

\section{Gestão jurídico-administrativa}

Esta é outra dimensão evidente na construção de estratégias de caráter técnico, para efetivação da intersetorialidade. Ela compreende protocolos intra setoriais, contemplando diferentes níveis de complexidade dos serviços - média e alta complexidade; protocolos intersetoriais; constituição de redes de políticas públicas envolvendo organizações da sociedade civil, sobretudo no campo da política social; regramento e formalização de rotinas, atribuições e competências funcionais, que parecem estar destituídos de dimensão política, entretanto, a portam em todos os níveis da organização.

Nesta dimensão, ainda persiste certo vazio de referenciais para a gestão, que privilegie o campo social, e, conforme afirma Dowbor, "os paradigmas de gestão que herdamos [...] têm todos, sólidas raízes industriais" (1999, p.36). A área social, por se configurar como política pública recentemente e, no seu âmbito, derivarem uma série de direitos que implicam políticas públicas correspondentes (a exemplo de direitos da criança e do adolescente; de idosos; de mulheres; de pessoas com deficiência; dentre outros), apresenta lacunas em sua gestão. Ou seja, "a grande realidade é que não sabemos como gerir estas novas áreas, pois os instrumentos de gestão correspondentes ainda estão engatinhando". (DOWBOR, 1999, p.36).

\section{Aproximações epistemológicas/conceituais da intersetorialidade}

As duas principais referências epistemológicas que localizamos em nossos estudos são tecidas por Pereira ${ }^{5}$ (2004 e 2011) e por Inojosa (2001), utilizando-se das categorias interdisciplinaridade e transdisciplinaridade, respectivamente.

Pereira (2011) se ocupa de produzir reflexões sobre aproximações conceituais entre a intersetorialidade e a interdisciplinaridade. Para tal, se fundamenta em Japiassu, concordando que a "interdisciplinaridade surgiu da consciência de um estado de carência no campo do conhecimento causado pelo aumento exagerado das especializações" se apresentando como possibilidade de

\footnotetext{
${ }^{5}$ Pereira (2011) traz ao debate da intersetorialidade as categorias multidisciplinaridade e pluridisciplinaridade com ressalva de que ambas não atenderiam aos propósitos de inter-relação de setores, por se configurarem como "monólogos de especialistas" ou "diálogos paralelos", valorizando o saber disciplinar. Por essa razão não consideramos pertinente sua problematização no corpo do artigo.
} 
aglutinar saberes desconexos e independentes" (p.6). Enfatiza que a unidade de saberes produzidos pela interdisciplinaridade implica vínculos orgânicos entre especialidades e opções por dada visão de mundo, a qual será produzida no exercício do debate político e no reconhecimento dos próprios saberes disciplinares.

Para Inojosa (2001, p.102), a intersetorialidade ou transetorialidade é “expressão no campo das políticas públicas e das organizações, da transdisciplinaridade tal como tem sido discutida no campo do conhecimento científico". A autora define intersetorialidade como sinônimo de transetorialidade atribuindo a esta o conceito de "articulação de saberes e experiências, com vistas ao planejamento, para a realização e a avaliação de políticas, programas e projetos, com o objetivo de alcançar resultados sinérgicos em situações complexas”. (2001, p.105).

Reconhecemos o estágio atual do debate da transdisciplinaridade e sua potência para a geração de alternativas de trabalho mobilizadoras nas políticas sociais, porém ela ainda se configura como uma proposta de difícil realização. Portanto, diante de vários aspectos que atualmente caracterizam o trabalho nas políticas públicas ${ }^{6}$, em especial a sobrecarga de demandas, o limitado número de servidores a exemplo de áreas como a saúde, a assistência social, a educação, os restritos espaços de estudos e planejamento integrados - ainda que, em equipes multidisciplinares de um determinado setor, compreendido como processo primeiro na direção de debates e estratégias articuladas de ação intersetorial - consideramos ser pertinente trabalharmos sob a perspectiva da interdisciplinaridade.

O próximo item busca instigar o debate dos elementos ético-políticos que possam fundar o trabalho intersetorial, sob bases interdisciplinares, fornecendo subsídios à problematização teórica, mas fundamentalmente à gestão e coordenação desses processos.

\section{Dimensão ético-política da intersetorialidade}

Esta dimensão, como já explicitado anteriormente, se ocupa das problematizações acerca dos projetos ideo-políticos em disputa no espaço público e, por conseguinte, da cultura política dos atores em presença na cena pública.

Conforme nos lembra Bidarra (2009, p.485), a "decisão pela ação intersetorial traduz a intenção política de investir num processo socialmente construído" o qual demandará o esforço de conhecimento e compreensão da cultura e das práticas políticas dos atores que partilham desse empreendimento e inclusive a compreensão crítica de si próprio.

\footnotetext{
${ }^{6}$ Mas não apenas nos postos de trabalho do setor público, senão, limites decorrentes dos processos de reestruturação produtiva que na perspectiva da multifuncionalidade do trabalhador lhe atribui sobretrabalho, dentre tantos outros efeitos que não cabe pontuarmos neste momento.
} 
Compreendemos que problemas e necessidades humanas/sociais são multidimensionais e não encontram resolutividade de modo setorializado ou por simples mudanças na gestão pública, visto que há determinantes estruturais na produção das desigualdades sociais e sua superação implica em mudanças profundas no campo da economia. Entretanto, problematizar os elementos referenciais das práticas intersetoriais, especialmente no que toca à cultura política de seus atores, visando seu aprimoramento no espaço da gestão pública, pode trazer impactos relevantes no plano da inclusão social, da garantia de direitos sociais e da participação política da população.

Através dos projetos políticos podemos identificar as diferentes visões de mundo e expectativas que os sujeitos têm, para o viver em sociedade. É possível a constituição de alianças e redes de poder que atuam num processo de construção de hegemonia política numa ou noutra direção.

Se relembrarmos que na Grécia antiga a política indicava a "atividade humana que tinha como referência a esfera social, pública e cidadã" (PEREIRA, 2009, p.88), a qual, em certa medida, resultou cindida na modernidade, pela separação da esfera pública com o universo privado e pelo peso que este adquire na cultura ocidental, delegando ao Estado um poder interventivo bastante significativo sobre o espaço público, temos uma condição que contribui para a naturalização da política como ação de competência dos dirigentes estatais.

Tal naturalização gera como efeito sobre seus cidadãos, a perda da dimensão de poder que lhes cabe no espaço público. E, no caso brasileiro, certo velamento dos projetos que orientam o Estado e seus programas de governo, associado à excessiva carga burocrático-formal que passa a ocupar a ação dos atores políticos nas novas institucionalidades públicas (conselhos de políticas públicas), como requisitos para a sua participação política, têm efeito desmobilizador e de retração da participação dos sujeitos nesses espaços.

Neste sentido, na ação intersetorial que intenciona a redução das desigualdades e a ampliação de cidadania, é crucial considerar compromissos e posturas éticas que possibilitem alianças sob os princípios:

a) Liberdade de manifestação, estímulo aos debates políticos e às práticas que possibilitem autonomia e emancipação dos sujeitos sociais;

b) Defesa dos Direitos Humanos e dos Direitos Sociais. A concepção de direitos sociais é referenciada por autores como Dagnino (1994), como sendo "um direito a ter direitos", o que reforça o sentido do direito conquistado (em especial pela Constituição Federal de 1988), e inclui a “invenção criativa de novos direitos", possibilitando a efetiva participação da sociedade civil na vida política e no espaço público. É também o princípio que nos permite lutar pela superação de 
preconceitos e práticas repressivas e policialescas impregnadas em várias estruturas do Estado brasileiro;

c) Estímulo à participação social, entendida a dimensão de historicidade que implica tais processos. Desnaturalização das normativas jurídico-institucionais e das políticas públicas, apreendendo-as como construções históricas, resultantes da práxis política e criadora dos sujeitos sociais. Este princípio, permeando as relações com os atores que se ocupam das políticas públicas, possibilita evidenciar potências para novas práticas, superando a cultura política tradicional clientelista e patrimonialista;

d) Defesa dos serviços sociais públicos na consolidação da cidadania - operados como bens públicos e não atendendo a interesses privados. Os referenciais fundados na racionalidade da globalização competitiva transferem ao campo das políticas públicas a responsabilização pela assunção de modelos de gestão que são fundados na eficiência e eficácia técnica dos serviços, lançando mão de um discurso de profissionalização, privatização e terceirização de responsabilidades governamentais. Esta tendência imprime lógica mercantil a serviços de relevância social como a educação ${ }^{7}$, a saúde, a previdência social, a assistência social e devem ser alvo de resistências e críticas de atores políticos que têm em seus horizontes a universalização dos serviços sociais públicos.

Este princípio implica também na superação das práticas de servidores e políticos baseadas na lógica tradicional que envolve, segundo Oliveira (2009), “o uso de recursos públicos para atender interesses privados" (p.113), práticas assistenciais clientelistas "nas quais o acesso dos usuários aos bens, recursos e serviços se realiza por meio de relações pessoais entre estes e representantes do poder público, a quem passam a dever favores, frequentemente pagos através da fidelidade e lealdade políticas" (p.112), acionadas em momentos eleitorais.

\section{Dilemas da gestão intersetorial e saídas possíveis}

Na sequência, apontamos possíveis saídas aos dilemas da gestão intersetorial, as quais demandam maior aprofundamento de estudos, cumprindo, neste ensaio, a função de ampliar a pauta para do debate político e epistemológico da questão.

\footnotetext{
${ }^{7}$ A exemplo de retribuições salariais por meta alcançada, aos professores de escolas públicas, implementadas pelo município do Rio de Janeiro - com o objetivo de alunos alcançarem determinado desempenho no IDEB (Índice de Desenvolvimento da Educação Básica). O que desvirtua completamente o compromisso ético que deve orientar o servidor público no desempenho de suas atividades.
} 
Um dos elementos centrais a ser problematizado para a criação de possibilidades efetivas da gestão intersetorial está na reformulação do desenho jurídico administrativo do Estado brasileiro contemporâneo, avaliando-se quais são os entraves a novos formatos de ministérios ou secretaria, buscando superar a "[...] pirâmide hierarquizada e fatiada da estrutura governamental". (Inojosa, 2001, p. 107).

Estudos realizados sobre experiências brasileiras de novos desenhos governamentais municipais (SCHUTZ, 2009) sintetizam dilemas que envolvem, na sua consecução, diretamente os atores políticos desses processos. A autora explicita contradições

[...] entre a adesão dos novos dirigentes ao projeto de mudança e aos seus projetos políticos pessoais; a adesão dos funcionários ao projeto de mudança e os seus interesses corporativos; entre a adesão da população à oportunidade de ampliar o espaço de cidadania e o exercício de direitos e deveres cívicos e a expectativa de benefícios imediatos, de curto prazo e de caráter assistencialista. (SCHUTZ, 2009, p.31).

Outro aspecto, ainda neste campo normativo diz respeito aos limites legais do que se denomina "República Federativa", adentrando questões polêmicas como a autonomia dos Estados e Municípios, limites do atual formato tributário brasileiro e da descentralização políticoadministrativa, os quais geram burocratizações, morosidade na disponibilização de recursos, centralismo político etc.

Conforme Schutz (2009), dentre experiências identificadas e já construídas/formuladas sob a lógica da intersetorialidade associada à descentralização administrativa, todas advogam que se organizem estratégias intersetoriais sob um viés territorial. Faz menção a experiências a cidade de Fortaleza/CE, Curitiba/PR, Belo Horizonte/MG, Bertioga, Campinas, Limeira, Piracicaba e municípios da região do ABCD em São Paulo.

Sobre as experiências mencionadas e apresentadas como alternativas de governabilidade intersetorial, em que ocorre a criação de novos órgãos gestores, sem a supressão das antigas estruturas e apenas acrescendo instâncias intersetoriais, nos perguntamos: Em que medida isso burocratizaria ainda mais a máquina estatal pela inclusão de novas estruturas na hierarquia do município? Seria possível experienciar desenhos de governo completamente diferenciados, suprimindo as instâncias setoriais?

A presença de novo atores políticos, a exemplo dos conselhos de políticas públicas, dos integrantes de redes que se autogestionam e operam na interseção com o Estado, de representantes de movimentos sociais e de corporações profissionais, devem ser problematizadas. O expressivo número de atores políticos e sociais que interagem no espaço público, a diversidade de concepções 
e princípios éticos é suposta e a explicitação de suas compreensões sobre os serviços públicos fortalecerá ou não, as perspectivas intersetoriais.

Outras indagações que fazemos tem a ver com a opção pelo trabalho na perspectiva da territorialidade e sua relação com a existência de fóruns temáticos/setoriais. No uso desses meios de gestão (fóruns temáticos) não se corre o risco de particularizar demais a análise dos determinantes de uma dada questão e afastar as mediações necessárias de uma leitura macro-social? A abordagem territorial da realidade social é uma alternativa possível para evidenciação da multidimensionalidade dos problemas a serem enfrentados pelas políticas públicas, em suas interrelações? Os fóruns setoriais teriam, nessa lógica, uma contribuição complementar em relação às estratégias territoriais de atuação e contribuição fundamental, de caráter disciplinar ou até mesmo transdisciplinar na análise, em profundidade, da problemática em questão.

A ausência de gestão para processos intersetoriais se coloca como mais um dilema que segundo Raichelis (2008) requer coordenação das políticas sem perder-se a perspectiva democrática do compartilhamento de decisões com a sociedade civil. Complementarmente, Inojosa (2001, p.108) indica que "[...] além da base regional e da rede, o planejamento e a ação articulados requerem liderança".

Além da necessidade de liderança e coordenação, consolidar serviços de modo intersetorial demanda pensar a situação dos trabalhadores das políticas públicas. Os processos de municipalização e descentralização administrativa das políticas sociais, sem a correspondência de distribuição de recursos financeiros, têm, em certa medida, enfraquecido a organização e participação desses trabalhadores, seja pela precarização de contratos de trabalho que ocorrem em nível municipal, seja pela realidade de sobrecarga de atividades nos casos de municípios que possuem apenas um profissional de cada área específica, limitando o trabalho em equipe, seja setorialmente ou intersetorialmente. Por outro lado, os espaços institucionais tornam-se deficitários em função da cultura de especialistas que neles se gesta.

Partilhamos da afirmação de Teixeira e Paim (apud SCHUTZ, 2009, p. 32), de que a “[...] distribuição dos poderes técnico, administrativo e político que conformam as organizações públicas exigindo, consequentemente, clareza estratégica, conhecimento científico e produção de fatos políticos [...]" são imprescindíveis para a viabilidade de intervenções intersetoriais. Ou seja, a formação acadêmica e os processos de educação continuada de profissionais que atuam nas políticas públicas demandam conteúdos técnicos para a ação intersetorial, mas fundamentalmente conteúdos e debates políticos que motivem a explicitação de compromissos e novas práticas pautadas na ética pública. 
A intersetorialidade tem sido utilizada sob o discurso da escassez de recursos, para fortalecer a "imperativa necessidade de reformar a ação do Estado" (BIDARRA, 2009, p.487), pautada neste caso nas "reengenharias" que restringem direitos. É necessário deixar explícito que não é sob essa perspectiva que se colocam nossas proposições. O Planejamento deve preceder o orçamento e a este adequar-se por critérios de relevância social das ações e não o seu inverso.

Sob os argumentos de Sposati (2006, p. 134) advertindo para devida observância de que a “intersetorialidade na gestão pública significa adotar uma decisão racional no processo de gestão, cuja aplicação pode ser positiva ou não, e, considerando ressalvas de Bidarra (2009, p.485) de que “é necessária a combinação entre setorialidade e intersetorialidade, bem como o estabelecimento de graduações para a existência dessa última”, apresentamos a seguir uma de suas possibilidades.

A possibilidade de gestão intersetorial que vislumbramos, ainda que sob demanda de estudo de sua pertinência, se refere à constituição de desenhos administrativo-jurídicos de gestão municipal inovadores e audaciosos sob os seguintes aspectos:

a) Criação de órgãos executivos intersetoriais territorializados, com equipes interdisciplinares, operando sob estratégias participativas de poder/decisão;

b) Permanência, de modo reestruturado, de instâncias de suporte técnico-administrativo, contábil, financeiro e jurídico que sirvam de mediadores na organização burocrática local para atender aos orçamentos setorizados da estrutura federal de ministérios;

c) Redesenho das equipes de suporte de tecnologia de informação e comunicação social, para atuação sob perspectiva territorial, de modo articulado às demais equipes técnicas. Produção de sistemas de informação e materiais de comunicação que melhorem processos de gestão e se convertam em ferramentas de acesso a informações no campo dos direitos sociais, da atuação política e ampliem a participação dos cidadãos no "espaço da política";

d) Viabilização de condições para que as instâncias de concepção, deliberação e execução das políticas públicas possam se encontrar em espaços de gestão intersetoriais "institucionalidades", por territórios, ainda que mantidos os conselhos setoriais de políticas públicas, constituídos formalmente.

Esta lógica conferiria maior sentido à representação popular nos espaços institucionalizados de governança pública, pois os próprios sujeitos estariam "de frente" para suas realidades. Não significa estímulo à participação pelas lógicas imediatas que movem os sujeitos, mas, a partir delas, possibilitar o contato com os debates políticos setoriais, mas mais do que isso, o agir politicamente sob bases de princípios "públicos" na necessária eleição de prioridades de ação, bem como contribuiria, via este processo, com a instituição de outra cultura política na realidade brasileira. 
O desenho proposto, ainda que de modo preliminar e inicial, não se presta às práticas conservadoras ou liberais de gestão, mas a um projeto político que afirma a cidadania social, pois que, os instrumentos propostos portam a necessária partilha de poder, estímulo à autonomia política e reconstrução das liberdades dos sujeitos que os integram.

\section{Considerações finais}

Pela análise produzida neste ensaio, evidenciamos que os sentidos mais frequentemente atribuídos à intersetorialidade, são os de complementaridade de setores; de prática integrada; de articulação política na gestão pública; de otimização de recursos e/ou de trabalho com redes, sendo limitado o número de estudos que problematizam esta categoria sob sua dimensão política.

O tema da gestão intersetorial nos trouxe interrogações sobre o necessário repensar das práticas nas políticas públicas, sob a perspectiva da ética e da ação política dos sujeitos, mas também indicou a necessidade premente de reformulações no desenho jurídico administrativo do Estado brasileiro contemporâneo, em especial da estrutura da administração pública, de órgãos setoriais de execução, bem como de órgãos de controle social, a exemplo de conselhos de políticas públicas.

Ao analisarmos experiências concretas de ações intersetoriais, podemos afirmar que as experiências positivas descritas, são aquelas que em que as estratégias intersetoriais se estruturaram sob um viés territorial. Ou seja, instituições, órgãos e pessoal técnico responsáveis por políticas setoriais, se articulam em torno de um determinado fenômeno social, circunscrito a um dado território, sobre o qual as ações serão planejadas e executadas e, com a identificação e participação dos cidadãos diretamente interessados no processo. Por vezes, instâncias não executivas, a exemplo do Ministério Público e/ou Poder Judiciário, também se envolvem em ações intersetoriais, guardadas suas atribuições. Mencionamos a política urbana como exemplo de potencial a ser trabalhada intersetorialmente sob a perspectiva territorial, a qual, por sua complexidade e abrangência possui natureza intersetorial.

$\mathrm{Na}$ perspectiva de uma reorganização administrativa para consolidação das políticas públicas por território, seria um grande avanço, em termos de gestão, a alocação administrativa de servidores públicos, por territórios, tanto sob a perspectiva da continuidade do trabalho, do estabelecimento de vínculos com os cidadãos - moradores locais, quanto para o aprimoramento dos serviços prestados à população. Pois constatamos, em análises resultantes de monitoramento e 
avaliação das políticas sociais, em sua implementação local, inúmeras críticas às descontinuidades das ações e dos serviços, tanto pela mudança de gestores, quanto pela rotatividade de técnicos nos equipamentos e serviços. Ademais, o não estabelecimento de vínculos, desses técnicos com a população usuária dos serviços, dificulta a participação ativa e cidadã dos sujeitos diretamente interessados na política pública, restringindo as decisões ao staff técnico e aos interesses de dirigentes políticos. Tal perspectiva de trabalho gera políticas públicas gestadas em gabinetes, com tendência à padronização de respostas e intervenções estatais pautadas centralmente no conhecimento técnico, mas que não respondem à complexidade de fenômenos que a vida nas cidades e nas comunidades rurais exigem. Resultando assim na não efetividade de inúmeras políticas públicas.

Concretamente, as práticas intersetoriais ainda figuram como experimentos focados na dimensão gerencial, carecendo avaliações mais detalhadas desses processos, à luz de referências que possibilitam a compreensão das políticas públicas, centralmente em sua dimensão normativa - a qual não separa valores e técnicas nas ações de governos. Por tais razões, ressaltamos que a formação acadêmica e os processos de educação continuada de agentes que atuam nas políticas públicas, demandam conteúdos técnicos para a ação intersetorial, mas fundamentalmente conteúdos e debates políticos que motivem a explicitação de compromissos e novas práticas pautadas na ética pública.

Temos convicção de que, por mais inovadoras e comprometidas socialmente com os princípios éticos - pontuados no segundo tópico deste trabalho, as experiências intersetoriais na gestão das políticas públicas não resolvem os problemas estruturais de natureza econômica da sociedade, mas possibilitam evidenciar projetos políticos inclusivos e situados num campo de defesa de direitos.

\section{Referências}

AVRITZER, L. e NAVARRO, Z. (orgs.). A inovação democrática no Brasil: o orçamento participativo. São Paulo: Cortez, 2003.

BIDARRA, Z. Pactuar a intersetorialidade e tramar as redes para consolidar o sistema de garantia dos direitos. Serviço Social e Sociedade, São Paulo, Cortez, n. 99, jul/set 2009, p.483-497.

BOURGuignON, J. A. Concepção de rede intersetorial. 2001. Disponível em: http://www.uepg.br/nupes/intersetor.htm. Acesso em: 17 Jun. 2011. 
BRASIL, Constituição da República Federativa do Brasil. 42. ed. atual. e ampl. São Paulo: Saraiva, 2009.

COUTO, B. R. O direito social e a assistência social na sociedade brasileira: uma equação possível? 3. ed. São Paulo: Cortez, 2008.

DAGNINO, E. (Org.). Anos 90: política e sociedade no Brasil. São Paulo: Brasiliense, 1994.

DOWBOR, L. A gestão social em busca de paradigmas. In: RICO, E. e RAICHELIS, R. (orgs.).

Gestão Social: uma questão em debate. São Paulo: EDUC; IEE, 1999.

INOJOSA, R. M. Sinergia em políticas e serviços públicos: desenvolvimento social com intersetorialidade. Cadernos Fundap, São Paulo, n. 22, 2001, p. 102-110.

INOJOSA, R. M.; JUNQUEIRA, L. P. Experiências Municipais: Desenvolvimento social e intersetorialidade na gestão pública municipal. Conferência Nacional de Saúde on line. 1997. Disponível em: http://www.datasus.gov.br/cns/inovador/MUNICIPAIS.htm. Acesso em 06 de junho de 2011.

JUNQUEIRA, L. A. P. A gestão intersetorial das políticas sociais e o terceiro setor. Saúde e Sociedade, v.13, n.1, jan/abr 2004, p.25-36.

JUNQUEIRA, L. A. P.. Novas formas de gestão na saúde: descentralização e intersetorialidade. Saúde e Sociedade [online]. 1997, vol.6, n.2, pp. 31-46.

NEVES, A. V. Cultura política e democracia participativa: um estudo sobre o orçamento participativo. Rio de Janeiro: Gramma, 2008.

OLIVEIRA, I. M. Cultura política, direitos e política social. In: BOSCHETTI, I. et al (orgs.). Política social no capitalismo: tendências contemporâneas. 2.ed. São Paulo: Cortez, 2009.

PEREIRA, P. A. P. Como conjugar especificidade e intersetorialidade na concepção e implementação da política de assistência social. Serviço Social e Sociedade, São Paulo, Cortez, n. 77, mar 2004.

PEREIRA, P. A. P. Discussões conceituais sobre política social como política pública e direito de cidadania. In: BOSCHETTI, I.et al (orgs.). Política social no capitalismo: tendências contemporâneas. 2.ed. São Paulo: Cortez, 2009.

PEREIRA, P. A. P. A intersetorialidade das políticas sociais numa perspectiva dialética. Mimeo, 2011.

RAICHELIS, R. Processos de articulação na perspectiva sócio-territorial. In: ARREGUI, C. C.; BLANES, D. N. (orgs.). Metodologias do trabalho social. São Paulo: IEE/PUC-SP, 2008, p. 209216.

SADER, E. Direitos e esfera pública. Serviço Social e Sociedade, São Paulo: Cortez, n. 77, mar 2004. 
SCHUTZ, F. A intersetorialidade no campo da política pública: indagações para o Serviço Social. 2009. Monografia (Graduação em Serviço Social) - Universidade Federal de Santa Catarina, Florianópolis, 2009

SPOSATI, A. Especificidade e intersetorialidade da política de assistência social. Serviço Social e Sociedade, São Paulo: Cortez, n. 77, mar 2004.

SPOSATI, A. Gestão política intersetorial: sim ou não? Comentários de experiência. Serviço Social e Sociedade, São Paulo, n. 85, mar 2006.

Artigo recebido em 07/10/2018. Aceito para publicação em 15/12/2018. 